\title{
APLIKASI MUSEUM SANG NILA UTAMA BERBASIS MOBILE DENGAN TEKNOLOGI 3D AUGMENTED REALITY
}

\author{
Agung Marinda'), Yoyon Efendi ${ }^{2)}$ \\ ${ }^{1,2}$ Teknik Informatika, STMIK Amik Riau, Jl. Purwodadi Indah Km 10 Pekanbaru \\ email: ${ }^{1}$ agungmarinda@gmail.com, ${ }^{2}$ yoyonefendi@stmik-amik-riau.ac.id
}

\begin{abstract}
The main Sang Nila Museum is one of the tourist destinations in Riau Province. In this museum there are 3,819 collections consisting of 10 types of cultural collections. Only 175 visitors each month are dominated by school children and students, besides that the lack of use of technology in service to visitors is a problem in the museum. Interactive technology is needed that is interesting and has an educational impact in attracting visitors to the museum. The research methodology uses interactive multimedia design with procedural methods. Starting from the background, goals, data collection, design concepts, making the main components and applications. Supported by the use of mobile devices that can be used wherever and whenever. The existing mobile application is capable of displaying tourist information that can be accessed anytime via a smartphone. Making begins with collecting museum data and images as a model using Sketch-up Software. The design of this augmented reality application uses Unity software by designing Markerless made using Vuforia. The feature in this application is to display some details of the Main Sang Nila Museum information that will be displayed in $3 D$ with animations using Augmented Reality. The introduction of the main Nila museum application is useful for people who want to travel to be able to see museum objects to be visited and get to know more closely about the museum's objects. Museum applications can run well by using a smartphone with high specifications that have a Gyroscope sensor.
\end{abstract}

Keywords: Museum, Mobile, 3D, Augemented Reality

\begin{abstract}
Abstrak
Museum Sang Nila utama merupakan salah satu destinasi wisata di Provinsi Riau. Pada museum ini menampilkan 3.819 koleksi yang terdiri dari 10 jenis koleksi budaya. Hanya 175 pengunjung setiap bulannya yang didominasi oleh anak sekolah dan mahasiswa, disamping itu kurangnya penggunaan teknologi dalam pelayanan kepada pengunjung menjadi masalah pada museum. Diperlukan teknologi interaktif yang menarik dan memberikan dampak edukasi dalam menarik minat pengunjung ke museum. Metodologi penelitian ini menggunakan desain multimedia interaktif dengan metode prosedural. Mulai dari latar belakang, tujuan, pengumpulan data, konsep desain, pembuatan komponen utama dan aplikasi. Ditunjang dengan penggunaan perangkat mobile yang bisa digunakan dimanapun dan kapanpun. Aplikasi mobile yang ada saat ini mampu menampilkan infomasi wisata yang dapat diakses kapanpun lewat smartphone. Pembuatan diawali dengan mengumpulkan data dan gambar museum sebagai model menggunakan Software Sketch-up. Perancangan aplikasi augmented reality ini menggunakan software Unity dengan merancang Markerless yang dibuat menggunakan Vuforia. Fitur dalam aplikasi ini adalah menampilkan beberapa detail informasi Museum Sang Nila Utama yang akan ditampilkan secara 3D dengan animasi menggunakan Augmented Reality. Pengenalan aplikasi museum sang nila utama ini, berguna bagi masyarakat yang ingin berwisata agar dapat melihat benda-benda museum yang akan dikunjungi dan mengenal dengan lebih dekat objek museum tersebut. aplikasi Museum dapat berjalan dengan baik dengan menggunakan smartphone dengan spesifikasi tinggi yang mempunyai sensor Gyroscope.
\end{abstract}

Kata Kunci : Museum, Mobile, 3D, Augemented Reality 


\section{PENDAHULUAN}

Museum adalah institusi permanen, nirlaba, melayani kebutuhan publik, dengan sifat terbuka, dengan cara melakukan usaha pengoleksian, mengkonservasi, meriset, mengomunikasikan, dan memamerkan benda nyata kepada masyarakat untuk kebutuhan studi,pendidikan dan kesenangan (Banjarnahor et al., 2016).

Salah satu museum yang berada di provinsi Riau yaitu Museum Sang Nila Utama. Museum Sang Nila Utama merupakan sebuah museum budaya melayu yang terletak di kota Pekanbaru, Provinsi Riau. Museum ini mengumpulkan dan menyimpan warisanwarisan yang berhubungan dengan budaya melayu riau seperti pakaian adat pernikahan, permainan tradisional, instrument-instrumen music dan artefak-artefak tradisional lainnya(Hafizh, Nasution, \& Haryono, 2018).

Museum menghadapi masalah dengan berkurangnya pengunjung. Salah satu penyebabnya, lemahnya pelayanan yang diberikan kepada pengunjung. Mulai dari segi informasi dan teknologi dalam menyampaikan koleksi museum. Diperlukan media dan teknologi yang dapat menarik minat wisatawan ke museum.

Salah satu media yang dapat digunakan berupa teknologi aplikasi mobile. Teknologi mobile salah satu perangkat teknologi yang perkembangannya sangat pesat, hal ini didorong perangkat mobile yang multifungsi, selain alat komunikasi, mobile menjadi salah alat pencari informasi yang paling banyak digunakan saat ini (Simatupang, Julianto, 2018). Dengan aplikasi mobile, pengunjung dapat mengakses dan interaktif dengan museum secara aktif. Dalam teknologi mobile didukung oleh 3 jenis yaitu Augmented Reality, Virtual Reality dan Mix Reality.

Teknologi Augmented Reality merupakan sebuah teknologi terobosan di bidang teknologi multimedia, dimana memanfaatkan objek 3D terangkat seolah-olah tampak seperti nyata. Penerapan teknologi ini sudah sampai pada tahapan penggunaan di PC hingga perangkat mobile(Pradnyana et al., 2017).

Augmented Reality dapat dikategorikan menjadi dua berdasarkan ada atau tidaknya penanda (marker) yaitu Marker Based Augmented Reality dan Markerless Based
Augmented Reality. Marker merupakan sebuah gambar dengan pola unik yang dapat diambil dengan kamera serta dapat dikenali oleh aplikasi Augmented Reality(Gusman \& Apriyani, 2016).

Hasil aplikasi berupa aplikasi Augmented Reality (AR) menggunakan metode Markerless User Defined Target (UDT) yang mampu menampilkan Museum Sang nila utama secara 3D tanpa menggunakan marker khusus pada perangkat android. Dengan metode Markerless User Defined Target yang didalamnya terdapat fitur berbasis Ground Plane yang dapat memudahkan dalam pemanfaatan teknologi Augmented Reality Museum Sang Nila Utama tanpa harus menggunakan Marker.

Secara umum definisi Augmented Reality yaitu menggabungkan dunia nyata dan dunia virtual, berinteraksi secara Real-Time dalam bentuk 3D (Asfari, Setiawan, \& Sani, 2012). Augmented Reality telah diterapkan pada berbagai bidang, seperti pendidikan, kedokteran, hiburan, militer, desain, robotik, dan lain-lain. Augmented Reality juga telah diaplikasikan dalam perangkat-perangkat yang digunakan oleh banyak orang seperti pada ponsel.

Promosi adalah bagian dan proses strategi pemasaran sebagai cara untuk berkomunikasi dengan pasar, dengan menggunakan komposisi bauran promosi / promotional mix (Tasruddin, 2015). Dengan adanya aplikasi ini dapat menjadi media promosi museum dengan menggunakan teknologi. Selain itu sebagai media edukasi bagi pelajar dan mahasiswa untuk mengunjungi meseum.

\section{METODE PENELITIAN}

Dalam penelitian multimedia salah satu teknik yang digunakan adalah multimedia interaktif. Multimedia interaktif merupakan kumpulan dari beberapa media seperti tesk, gambar, audio, video, dan animasi yang bersifat interaktif yang digunkan untuk menyampaikan informasi(Nopriyanti, 2015).

Multimedia interaktif suatu multimedia yang dilengkapi dengan alat pengontrol yang dapat dioperasikan oleh pengguna, sehingga pengguna dapat memilih apa yang dikehendaki untuk proses selanjutnya. Contoh multimedia interaktif adalah: multimedia pembelajaran interaktif, 
aplikasi game, dan lain-lain(Widiatno, Rizki, 2014).

Metode penelitian yang digunakan pada penelitian ini yaitu desain multimedia interaktif dengan metode prosedural. Model prosedural merupakan model yang bersifat deskriptif, yaitu menggariskan langkahlangkah yang harus diikuti untuk menghasilkan produk. Dapat digambarkan pada diagram berikut:

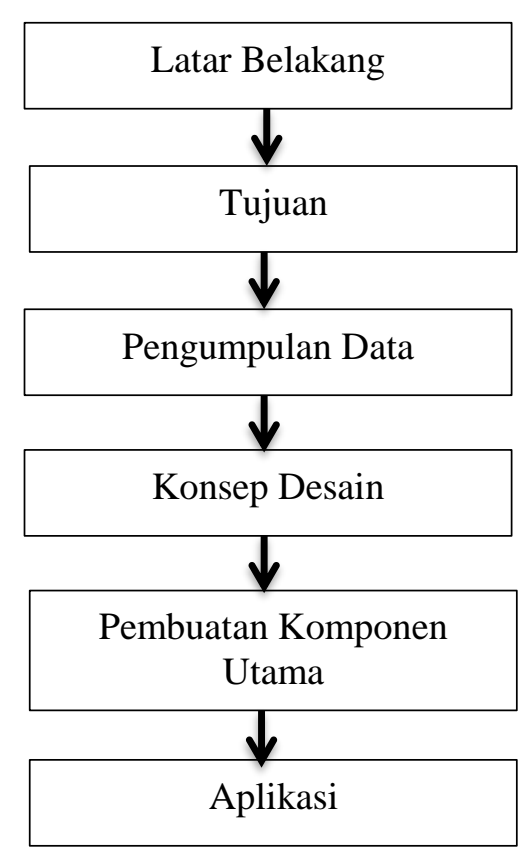

Gambar 1. Model Prosedural

\subsection{Metode Prosedural}

Perancangan desain Multimedia interaktif dengan metode prosedural dimulai dari latar belakang, tujuan, pengumpulan data, konsep desain, pembuatan komponen utama dan aplikasi.

\section{Latar Belakang}

Latar belakang pembuatan aplikasi ini menurunnya jumlah pengunjung museum karena kurangnya pelayanan. Disamping itu juga media promosi yang disampaikan masih dalam bentuk web dan brosur. Diperlukan teknologi yang dapat menarik pengunjung untuk datang ke museum.

2. Tujuan

Tujuannya untuk menghasilkan aplikasi media interaktif 3D berbasis Augmented Reality museum Sang Nila Utama. Disamping itu juga sebagai media edikasi dan promosi budaya Melayu Riau.

3. Pengumpulan Data
Teknik pengumpulan data melakukan observasi langsung ke Museum Sang Nila Utama dan Wawancara dengan narasumber dengan pimpinan dan staf museum.

4. Konsep Desain

Konsep desain aplikasi museum dengan membuat beberapa menu. Menu ini dapat dilihat pada gambar 2 dibawah ini:

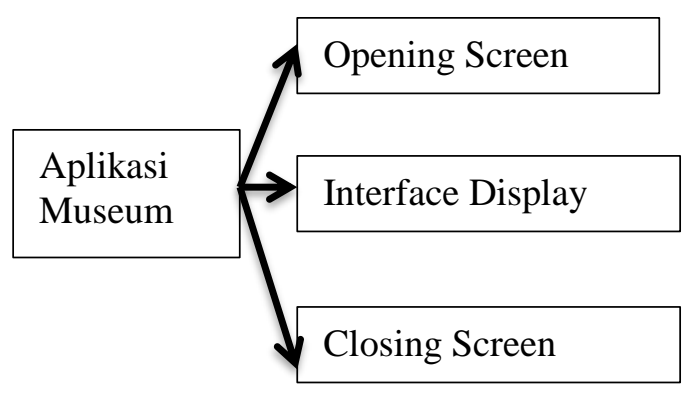

Gambar 2. Diagram konsep desain

Pada konsep desain aplikasi museum terdiri dari 3 menu yaitu pada menu Opening screen didalamnya terdapat judul dan menu. Pada menu Interface Display didalamnya terdapat menu kamera ground plane dan beberapa icon. Dan terakhir ada menu Closing Screen.

\section{Pembuatan Komponen Utama}

Pada pembuatan komponen utama dalam bentuk menu utama yaitu desain Opening, Animasi 3D dan Closing.

\section{Desain Opening Screen}

Tampilan pertama yang di sajikan pada aplikasi Augmented Reality museum sang nila utama ini adalah tampilan opening. Dapat dilihat pada gambar 3 di bawah ini :

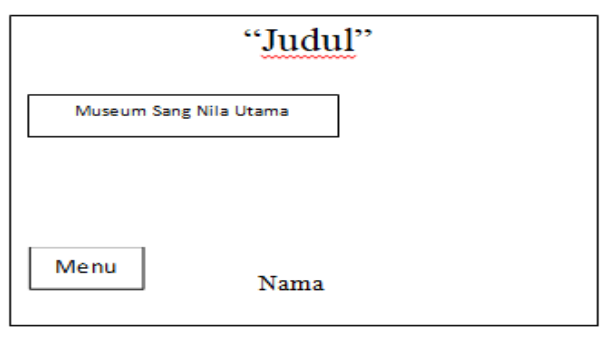

Gambar 3. Opening Screen 


\section{Desain Interface Display}

Pada tampilan ini akan menyajikan museum sang nila utama yang telah discan dengan teknik Ground Plane, tampilan ini terdapat beberapa button Icon mulai dari deksripsi, objek benda, sound, lantai 1, lantai 2 dan lokasi. Dapat dilihat pada gambar 4 di bawah ini :

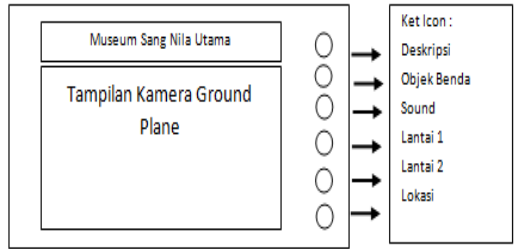

Gambar 4. Interface Display

\section{Desain Closing}

Pada tampilan ini adalah sesi dari penutup pada aplikasi Augmented Reality museum sang nila utama. Dapat di lihat pada gambar 5 di bawah ini :

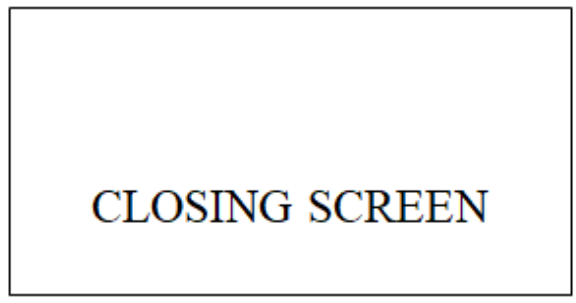

Gambar 5. Closing Screen

\section{Aplikasi}

Pada aplikasi dibangun dapat dijalankan pada Smartphone. Berikut ini adalah gambaran umum dari sistem. Dapat dilihat pada gambar 6. Dibawah ini:

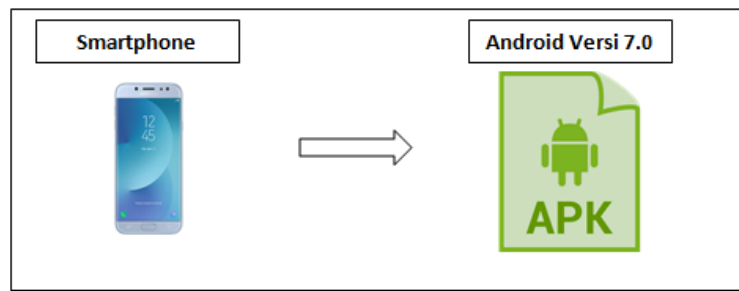

Gambar 6. Alur Kerja Perangkat Lunak

Alur kerja perangkat lunak yang di tunjukan dari Gambar 5 menunjukan bahwa untuk menjalan aplikasi Augmented Reality museum sang nila utama 3D, haruslah didukung oleh smartphone yang menggunakan sistem operasi Android Versi 7.0 dan mendukung dalam menjalankan aplikasi Augmented reality.

Proses desain aplikasi menjelaskan tahapan dari pembuatan aplikasi mulai dari awal pembuatan objek tiga dimensi sampai proses membuat aplikasi Augmented Reality museum sang nila utama 3D ( tiga dimensi). Berikut ini adalah gambaran dari proses desain aplikasi. Dapat dilihat pada gambar 7 dibawah ini:

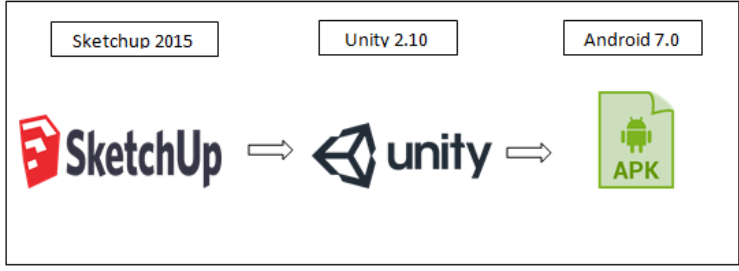

Gambar 7. Proses Desain Aplikasi

Dari gambar proses desain aplikasi yang di tunjukan Gambar 7 menunjukan bahwa proses desain dimulai dengan membuat object animasi menggunakan aplikasi Sketchup. Aplikasi Sketch-up digunakan sebagai media untuk mengolah objek tiga dimensi, dimulai dengan objek cube yang akan di olah sehingga menyerupai bentuk objek yang di inginkan. Setelah menyerupai bentuk animasi 3D kemudian menambahkan detaildetail objek seperti teksture atau warna dari objek. Agar dapat di import kedalam Unity 3D simpan file dengan format (.obj).

Selanjutnya tahapan menggabungkan setiap model object 3D menjadi scene sebuah rancangan objek bangunan dan benda tiga dimensi dengan menggunakan software Unity 3D. Selanjutnya import file objek $3 \mathrm{~d}$ yang telah dibuat dengan sketchup, kemudian memindahkan objek kedalam jendela kerja unity dengan click and drop objek. Selanjutnya export project yang telah dibuat kedalam apk android dengan format (.apk). Tahapan selanjutnya manjalankan file yang telah di export dengan smarphone.

\subsection{Hirarki Menu}

Hirarki menu adalah gambaran menu yang dapat diakses oleh user. Adapun gambar hirarki menu program dapat dilihat pada gambar 8 dibawah ini : 


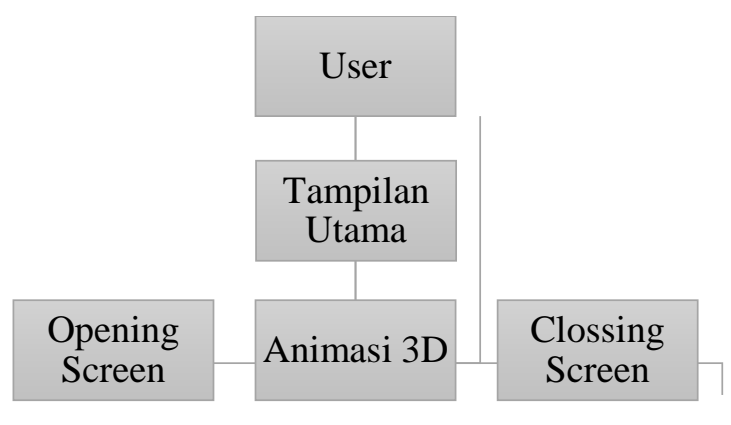

Gambar 8. Hirarki Menu Aplikasi

\section{HASIL DAN PEMBAHASAN}

Dalam rancangannya menggunakan Google Sketchup untuk membangun objek dalam bentuk tiga dimensi. Dalam perancangannya aplikasi tersebut berhubungan dengan format yang sesuai dengan aplikasi Unity Engine.

Untuk dapat di akses di perlukan smartphone yang sudah mampu menjalankan Augmented Reality dan telah mampu menjalankan fitur Ground Plane dimana aplikasi tersebut akan menampilkan hasil perancangan pada bidang datar yang akan dideteksi secara otomatis Spesifikasi perangkat lunak yang dibutuhkan agar untuk membangun aplikasi dan membuat aplikasi ini berjalan optimal sebagai berikut :

1. Aplikasi Google Sketchup 2015

2. Aplikasi Unity $3 D$ versi 2.5 (64-bit)

3. Operating sistem dengan spesifikasi windows 864 Bit.

4. Android 7.0 Nougat

\subsection{Objek 3D pada Google Sketch-up}

Untuk menghasilkan objek 3D yang akan ditampilkan pada sistem dilakukan perancangan pada aplikasi Google Sketchup. Objek 3D didesain sedemikian rupa agar dapat mewakili objek aslinya yang akan ditampilkan pada aplikasi. museum sang nila utama terdiri dari 2 tampilan yaitu Tampilan keseluruhan secara lengkap dengan halaman sekitar dengan objek interior dan dalam Museum dengan interior.

\section{Museum Sang Nila Utama secara keseluruhan}

Tampilan yang terlihat Museum Sang Nila Utama secara keseluruhan dengan halaman. Dapat dilihat pada gambar 9 dibawah ini:

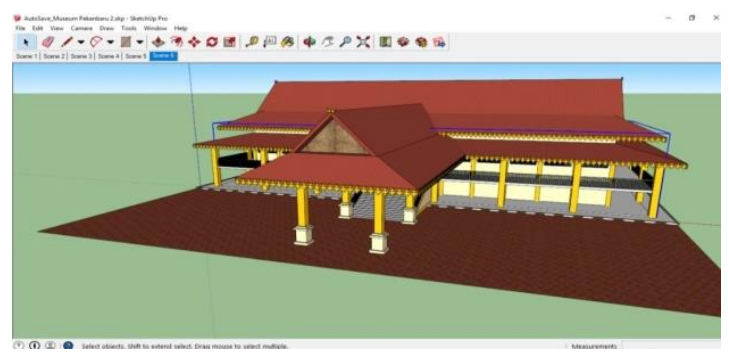

Gambar 9. Museum Sang Nila Utama Keseluruhan

\section{Kondisi di dalam Museum Sang Nila Utama}

Tampilan pada dalam dilengkapi dengan objek objek interior yang merupakan gambaran langsung pada kondisi aslinya. Dapat dilihat pada gambar 10 sebagai berikut:

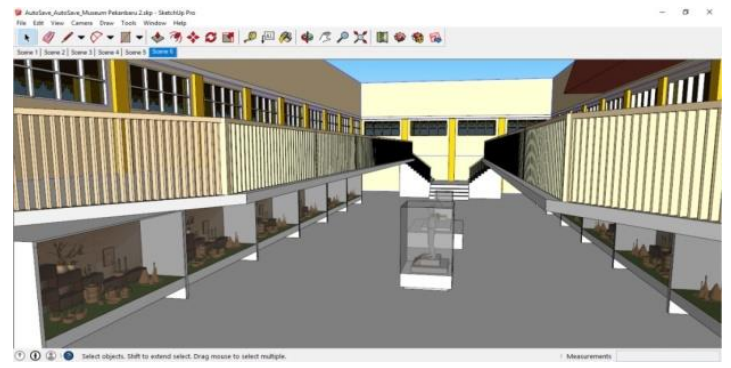

Gambar 10. Dalam Museum dengan interior

Terdapat objek interior didesain sedetail mungkin agar dapat menyerupai objek aslinya. Objek benda museum berupa meriam dan keris atau pedang kuno seperti gambar 11 dibawah ini:

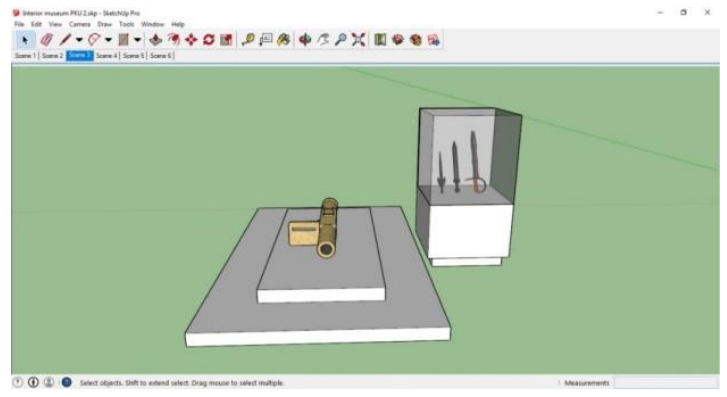

Gambar 11. Desain Objek Interior

Objek 3D Museum Sang Nila Utama yang sudah dibangun pada aplikasi Sketchup diexport menjadi objek dan kemudian diimport pada aplikasi Unity dan ditempatkan tepat 
diatas Ground Plane. Hasil importing objek 3D pada aplikasi dapat dilihat pada gambar 12 dibawah ini:

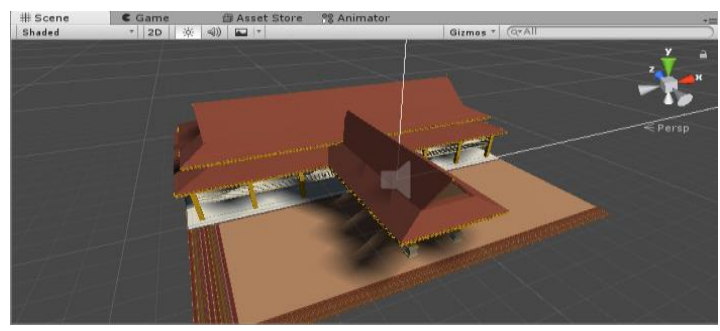

Gambar 12. Importing Objek 3D pada aplikasi

Sama halnya dengan Objek museum sang nila utama, pada objek interior diexport menjadi objek dengan ekstention Obj dan kemudian diimport pada aplikasi Unity dan ditempatkan tepat diatas Ground Plane, yang nantikan akan ditampilkan menggunakan tombol navigasi. Dapat dilihat pada gambar 13 dibawah ini:

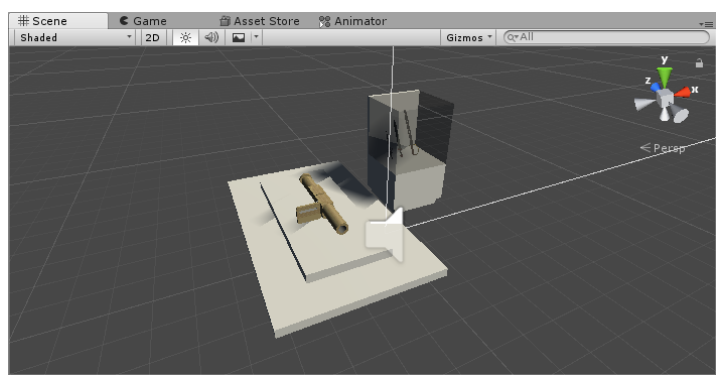

Gambar 13. Importing Objek 3D Interior

\subsection{Aplikasi Berbasis Ground Plane}

Pada tahapan Aplikasi Berbasis Ground Plane, Aplikasi dirancang menggunakan aplikasi Unity Engine dan Vuforia 7.2 yang telah menyediakan fiture Ground Plane, dimana Ground Plane merupakan sebuah fiture yang dapat mendeteksi suatu bidang datar secara otomatis dengan demikian objek 3D yang telah di desain sebelumnya akan ditampilkan pada Ground Plane.

Pada bagian menu utama di rancang dengan menampilkan 1 button, dapat dilihat pada gambar 14 dan gambar 15 detail informasi sebagai berikut:

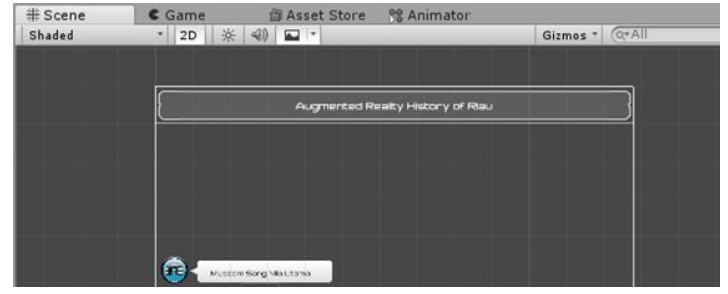

Gambar 14. Menu Utama

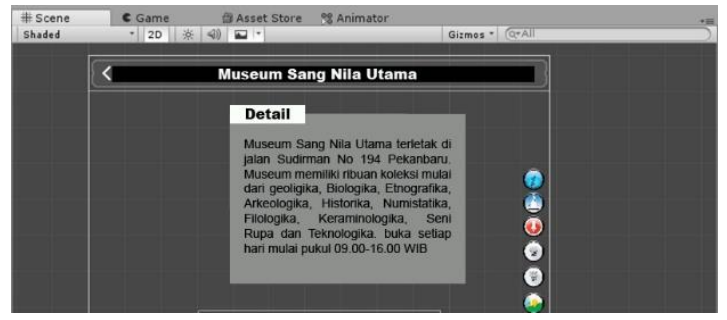

Gambar 15. Мепи Objek detail Museum

Panel deskripsi diposisikan pada tengah scene agar dapat dengan mudah terbaca oleh pengguna, dan pada panel deskripsi dapat discrol atas dan bawah sehingga deskripsi setiap objek yang ditampilkan akan dapat terbaca secara keseluruhan. Menu pada navigasi dapat dilihat pada gambar16 dibawah ini:

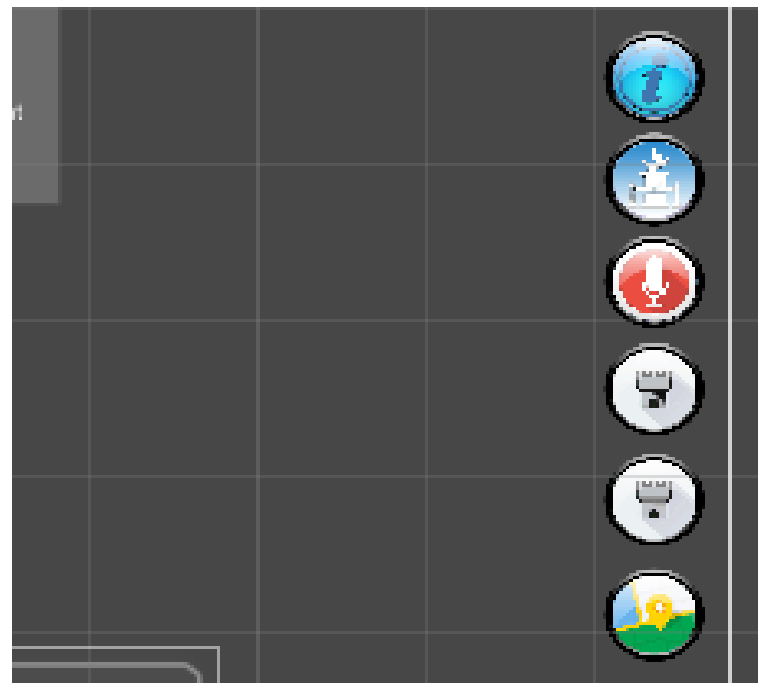

Gambar 16. Мепи

Menu navigasi diposisikan pada sebelah kanan layar, dimana setiap button navigasi memiliki fungsi masing masing dan setiap scene memiliki jumlah button yang berbeda. 
Tabel 1. Menu Sistem

\begin{tabular}{|c|c|c|}
\hline No & Icon & Deksripsi \\
\hline 1 & & $\begin{array}{l}\text { Menampilkan menu } \\
\text { navigasi utama, yang } \\
\text { befungsi untuk } \\
\text { mengarahkan } \\
\text { pengguna pada } \\
\text { objek yang diinginkan. }\end{array}$ \\
\hline 2 & & 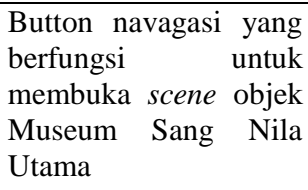 \\
\hline 3 & & $\begin{array}{l}\text { Button navagasi yang } \\
\text { berfungsi untuk } \\
\text { menampilkan dan } \\
\text { menyembunyikan } \\
\text { deskripsi dari setiap } \\
\text { objek yang ditampilkan }\end{array}$ \\
\hline 4 & & $\begin{array}{lr}\text { Button navagasi } & \text { yang } \\
\text { berfungsi } & \text { untuk } \\
\text { menampilkan dan } \\
\text { menyembunyikan } \\
\text { lantai pada objek } \\
\begin{array}{ll}\text { Museum Sang Nila } \\
\text { Utama }\end{array} \\
\end{array}$ \\
\hline 5 & & $\begin{array}{lr}\text { Button navagasi yang } \\
\text { berfungsi } & \text { untuk } \\
\text { menampilkan dan } \\
\text { menyembunyikan } \\
\text { objek interior yang } \\
\text { telah disediakan }\end{array}$ \\
\hline 6 & & $\begin{array}{l}\text { Button navagasi yang } \\
\text { berfungsi untuk } \\
\text { memulai penjelasan } \\
\text { suara dari setiap objek }\end{array}$ \\
\hline 7 & & $\begin{array}{lr}\text { Button navagasi yang } \\
\text { berfungsi } & \text { untuk } \\
\text { mengarahkan } & \\
\text { pengguna } & \text { kepada } \\
\text { lokasi objek } & \end{array}$ \\
\hline
\end{tabular}

\section{3 Hasil dan Implementasi}

Pada tahapan hasil dan implementasi aplikasi diujikan pada smartphone yang telah dapan menjalakan fiture Ground Plane dari Vuforia, dimana aplikasi diujikan pada smartphone Samsung J7 Pro dan Versi Android 7.0 Nougat, selain smartphone tersebut aplikasi hanya dapat berjalan pada smartphone yang telah masuk didaftar Vuforia Fusion Supported Device.
Pada menu utama dilakukan uji coba dengan melakukan show dan hide menu navigasi lainnya dan setiap button navigasi dapat meload setiap scene dari ke 3 scene utama yang telah dirancang. Scene museum sang nila utama dapat menampilkan objek museum sang nila utama secara keseluruhan, objek dapat dipindahkan, dizoom dan dirotate sehingga memudahkan pengguna berinteraksi dengan objek yang ditampilkan pada aplikasi. Dapat dilihat pada gambar 17 sebagai berikut:

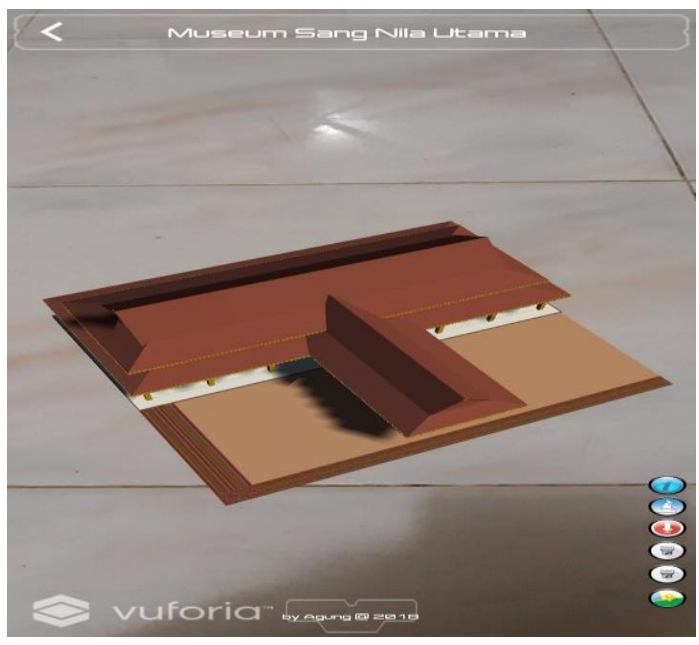

Gambar 17. Running Objek museum sang nila utama pada Ground Plane

Dengan mengaktifkan menu show lantai 1 pada button navigasi yang terdapat pada sebelah kanan layar maka aplikasi akan menampilkan interior pada lantai 1 museum sang nila utama. Dapat dilihat pada gambar 18 sebagai berikut:

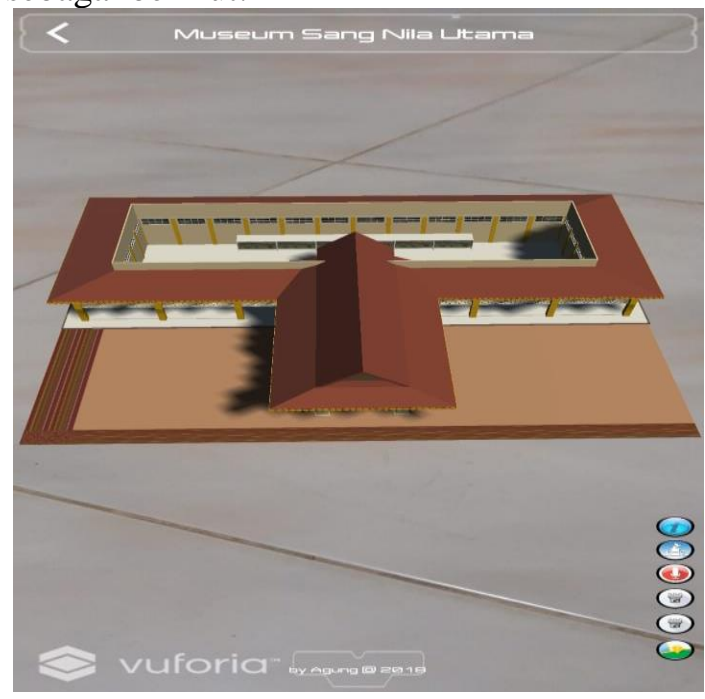

Gambar 18. Show dan Hide Lantai 1 Museum Sang Nila Utama 
Dengan mengaktikan button deskripsi maka panel deskripsi akan tampil tepat ditengah layar dan juga pengguna juga dapat mendengarkan deskripsi objek dengan voice yang telah disediakan dengan menekan button sound.

Untuk melihat objek interior secara khusus pengguna dapat menekan button objek dan aplikasi akan menampilkan objek interior secara khusus, pengguna dapat melihat dengan detail setiap interior yang ada dalamnya dengan mendekatkan kamera pada objek dan dapat mengelilingi objek tersebut. Dapat dilihat pada gambar 19 sebagai berikut:

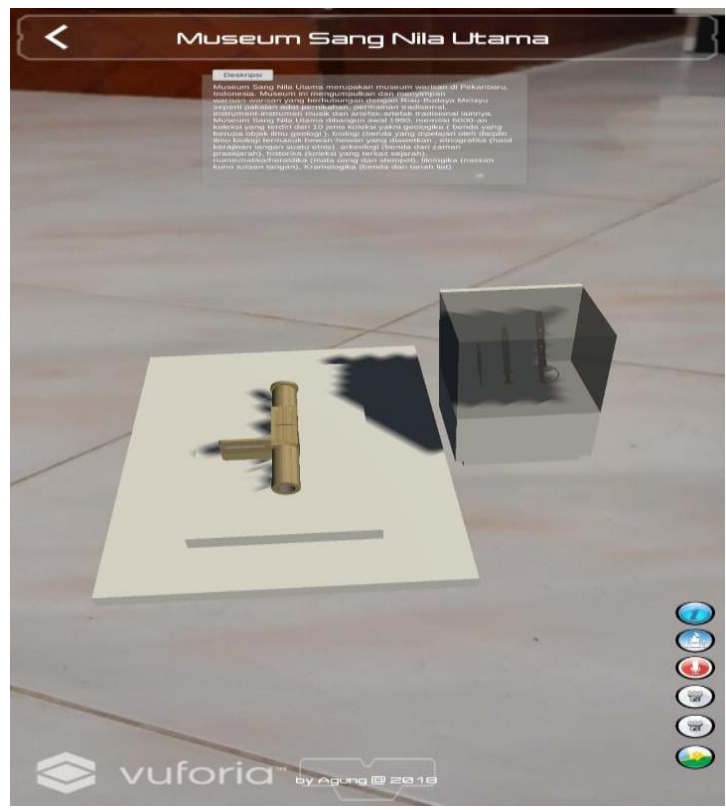

Gambar 19. Show dan Hide Objek museum sang nila utama

\section{SIMPULAN}

Dari hasil perancangan dan pengujian aplikasi yang telah dilakukan, maka dapat ditarik kesimpulan dapat dilihat pada tabel 2 sebagai berikut:

Tabel 2. Hasil Pengujian aplikasi AR

\begin{tabular}{|c|l|l|}
\hline No & Pengujian & Hasil \\
\hline 1 & Samsung J1 prime & $\begin{array}{l}\text { Tidak } \\
\text { berhasil }\end{array}$ \\
\hline 2 & Samsung J2 Prime & Berhasil \\
\hline 3 & Samsung J7 Pro & Berhasil \\
\hline 4 & $\begin{array}{l}\text { Asus Zenfone Max } \\
3\end{array}$ & Berhasil \\
\hline
\end{tabular}

Dari hasil pengujian dapat ditarik kesimpulan bahwa aplikasi Museum dapat berjalan dengan baik dengan menggunakan smartphone dengan spesifikasi tinggi yang mempunyai sensor Gyroscope. Dengan teknologi 3D Augmented Reality pada Museum Sang Nila Utama sebagai invovasi baru dalam mempromosikan objek wisata yang ada di Riau. Dengan pengembangan aplikasi dengan berbagai objek wisata lain di Provinsi Riau.

\section{UCAPAN TERIMAKASIH}

Diucapkan terimakasih kepada Kepala Dinas Kebudayaan Provinsi Riau dalam Hal Ini Kepala Museum Sang Nila Utama Pekanbaru sebagai objek penelitian. STMIK Amik Riau dalam hal ini LPPM STMIK Amik Riau yang memberikan masukan dan saran dalam penelitian ini

\section{DAFTAR PUSTAKA}

Asfari, U., Setiawan, B., \& Sani, A. (2012). Pembuatan Aplikasi Tata Ruang Tiga Dimensi Gedung Serba Guna Menggunakan Teknologi Virtual Reality [ Studi Kasus: Graha ITS Surabaya ]. Teknik Its, 1(1), 1-5. https://doi.org/10.12962/j23373539.v1i1 .1866

Banjarnahor, D., Ginting, M. F., Widyaningrum, I., Hidayati, H., Gozali, A. A., Terapan, F. I., \& Telkom, U. (2016). Toba Museum “ Museum Berbasis Virtual Reality Untuk Mempromosikan Kebudayaan Sumatera Utara." E-Proceeding of Applied Science, 2(2), 733-740.

Gusman, R., \& Apriyani, M. E. (2016). Analisis Pemanfaatan Metode Markerless User Defined Target Pada Augmented Reality Sholat Shubuh, 8(1), 64-70.

Hafizh, M. P., Nasution, T., \& Haryono, D. (2018). CITRA 2D SEBAGAI REPRESENTASI BENDA-BENDA BERSEJARAH PADA. JOISIE Journal Of Information System And Informatics Engineering, 2(2), 16-27.

Nopriyanti, P. S. (2015). PENGEMBANGAN MULTIMEDIA PEMBELAJARAN INTERAKTIF INTERACTIVE LEARNING 
MULTIMEDIA THE BASIC COMPETENCY IN INSTALLING LIGHTING AND. Jurnal Pendidikan Vokasi, 5(1).

Pradnyana, G. A., Pendidikan, J., Informatika, T., Ganesha, U. P., Reality, A., \& Pengenalan, M. (2017). PENGEMBANGAN APLIKASI AUGMENTED REALITY MARKERLESS PENGENALAN DAN TEKNIK DASAR BOLA BASKET, 6 .

Simatupang, Julianto, M. (2018). RANCANG BANGUN APLIKASI PENGELOLAAN TUGAS AKHIR DENGAN, 2(2), 39-48.

Tasruddin, R. (2015). STRATEGI PROMOSI PERIKLANAN YANG EFEKTIF. Jurnal Al-Khitabah, 2(2), 107-116.

Widiatno, Rizki, L. N. (2014). PENERAPAN MEDIA
MULTIMEDIA INTERAKTIF (MMI) PADA KOMPETENSI DASAR METODE DASAR MEMASAK UNTUK MENINGKATKAN HASIL BELAJAR SISWA SMK NEGERI 3 BLITAR. E-Journal Boga, 03(Mmi), 89-99.

Spesifikasi Android Augmented Reality (https://library.vuforia.com) 